\title{
CONCEITO DE INFECÇÃO EM CIRURGIA (*)
}

\author{
ARY SIQUEIRA \\ $10^{\circ}$ assistente
}

As infecçónes estudadas em - Clinica Cirurgica - em nada diferem das enfermidades infecciosas abordadas em - Clin ca Medica. Ambas são devidas, á presença no organismo, de, produtos toxicos, procedentes da atividade nutritiva de germens infecciosos. Esses germens, pertencem na sua maioria, a certas formas primitivas da vida - ás bacterias - microrgan smos dotados de capacidades metabolicas elementares mas, ativissimas.

$\mathrm{O}$ orgànismo hospedador, além de absorver os produtos toxicos elaborados pelo metabolismo bacteriano, fica privado de certos elementos, que são utilisados pelas bacterias.

Quando as substancias da atividade metabolica dos agentes infectantes estão em contraste com aquelas dos tecidos que ocupam, estes apresentam man festações, que caracterisam a - infecção - Entretanto, si a diferença entre os produtos do metabolismo bacteriano $e$, aqueles produzidos pelas trocas normais dos tecidos, é muito acentuada, pode passar' quasi inadvertida a presença local dos germens, porem os humores do organismo invadido, saturam-se de produtos extranhos ao seu metabolismo normal, dando lugar a reações gerais mais ou menos extensas. E esta a razão porque devemos diferenciar uma infecção local de uma infecção geral.

$\mathrm{Si}$ o organismo reage intensamente contra as mortificações em vida, produzidas pela ação deleteria das toxinas microbianas, o conjunto de fenomenos que integra tal reação é conhecido sob a denom:nação de - processo inflamatorio. Nestas condições a infecção diz-se local.

Contrariamente, quando os produtos do metabolismo do germe têm pequena toxicidade para os tecidos, passam mais facilmente para a circulação e teremos então, uma reação geral, reação essa que se manifesta em todo o organismo.

(*) Aula taquigrafada pelos alunos. 


\section{DELIMITAÇÃO DAS INFECÇÖES CIRURGICAS}

Qual é a delimitação e, o que deve ser estudado em Clinica Cirurgica, a respeito das infecções? No nosso estudo, deverão predominar as reações locais, principalmente as inflamações do tipo supurativo (afecções piogenas) e aquelas do tipo cronico como, por exemplo, as manifestações da tuberculose, da sifilis etc. nas afecções da pele, do tecido celular sub-cutaneo, muscular, osseo e articular. Devemos ademais, acrecentar como tipo de infecções com lesões locais, o furunculo, o antraz, o flegmão, além das molestias de manifestação geral, como o tetano, a raiva, etc., nas quais um simples ferimento dá origem a uma molestia grave è geral.

Devem tambem ser estudadas: a bacteremia e as molestias causadas por picadas de insetos, ofidios e flechas envenenadas.

\section{PROCESSO INFLAMATORIO}

\section{CONCEITO CLINICO E CONCEITO BIOLOGICO}

Todos nós sabemos o que é uma inflamação. Trata-se de um processo de que se têm geralmente, uma noção vulgar, porem dificil de definir cientificamente.

Desde a mais remota antiguidade, o homem poude observar, em determinadas condições, como algumas partes de seu organismo, adquiriam uma fogosidade especial, uma sensação de calor, tanto assim que esse fenomeno se registra em todas as linguas antigas ou modernas com nomes derivados de "chama ou "fogo".

$O$ primieiro autor de quem se tem memoria, ter dado uma definição á inflamação, foi Celsius, condensando-a nas quatro seguintes manifestações cardias: tumar, rubor, calor e dor.

Os sintomas acima, conservam ainda hoje, todo o seu valor para definir clinicámente o processo inflamatorio. Entretanto, existe entre os AA. um desacordo completo acerca do que se deve entender" por inflamação. Não é de extranhar consequentemente que, as definições se tornaram tão numerosas que si consultarmos as bibliografias recentes, ficaremos assombrados com o grande numero-de conceitos diversos.

Uma definição que considera satisfatoria é a seguinte: inflamação é o conjunto de fenomenos que se passam nos tecidos, como consequencia da reação a agentes capazes de alterar a sua estrutura fisico-quimica.

\section{CAUSAS DA INFLAMAÇÃO}

Estudando as causas produtoras da inflamação, poderemos comprender mais facilmente o que se entende por esse fenomeno. Anti- 
Gamente, a inflamação era considerada como a reação do organismo a um processo infeccioso. Entretanto, hoje em dia, sabemos que um processo inflamatorio se manifesta sempre de uma mesma maneira quer frente a germens, como de fronte a agentes fisicos e quimicos. Assim é que as ondas curtas, o raio $\mathrm{X}$, o oleo de croton, a essencia de terebentina e, numerosas outras substancias, provocam alterações coloidais no seio dos tecidos, determinando uma reação que nada mais é, sinão um procésso inflamatorio aseptico.

Ampliando a genese da inflamáção, supõem alguns $\mathrm{AA}$. que este processo é o modo geral de reação dos tecidos perante todos os excitantes externos.

$\mathrm{Na}$ realidade, para que se desencadeie o processo inflamatorio, é necessario a alteração do tecido, o que constitue o nucleo do processo.

Apesar dessas numerosas excepçōes, não poderemos deixar de dizer que na maioria dos casos, a inflamação é uma reação ao agente infeccioso.

\section{FISIO-PATOLOGIA DO PROCESSO INFLAMATORIO}

O processo inflamatorio caracterisa-se facilmente na sua fisiopatologia, por um aumento consideravel na atividade dos tecidos e, já Virchow definia a inflamação - como um estado de super-atividade patologica dos tecildos.

Quer observado a olho nú,' quer examinado ao microscopio, o substrato anatomo-patologico do processo inflamatorio pode ser analisado por fenomenos cardiais que se passam no seio do tecido inflamado, a saber:

$$
\begin{aligned}
& 1 \text { - hiperemia; } \\
& 2 \text { - exudação; } \\
& 3 \text { - migração leucocitaria } \\
& 4 \text { - neoformação celular. }
\end{aligned}
$$

Hiperemia - $\mathrm{O}$ primeiro A. a constatar cientificamente a hiperemia foi Hunter em 1795, realisando estudos classicos, na orelha do coelho. Chegou á conclusão que a inflamação era um fénomeno de congestão ativa.

As experiencias de Hunter, foram retomadas por Conhein sobre o mesenterio da זã, permitipdo-lhe determinar o desenvolvimento e o decurso da hiperemia inflamatoria.

Excitando o mesenterio da rấ, observava Conhein, que reagia por uma sèrie de fenomenos, descritos por Thomas Lewis como sendo a triade inflamatoria, pela qual os tecidos reagiam, primeiro por vaso-constriç̧ão capilat e, secundariamente por uma vaso-dilatação. Observou mais, que essa reação era absolutamnete constante nos tecidos e completamente livte dos processos circulaltorios gerais, processando-se mesmo na hipotese de haver um obstaculo á circula- 
ção. Isto vinha provar que o fenomeno da hiperemia, é uma reação autonoma dos tecidos e da propria parede capilar.

Mesmo afastando-se o orgão do corpo, em culturas de tecido, a reação se processava em seus minimos detalhes. Este fato veiu trazer a suspeita de que a hiperemia era motivada pela libertaçãode uma substancia vaso-ativa. Essa substancia foi estudada por Lewis, autor que verificou a possiblidade do fenomeno ser reproduzido experimentalmente pela histamina, que seria então a substancia libertada pelos tecidos lesados.

Modernamente, precisou-se melhor o mecanismo da hiperemia inflamatoria, graças aos trabalhos de Muller, Krogh e Magnus que, observaram que, a irritação de uma zona de tecido produz imediatamente uma vaso-constricção, seguida de vaso-dilatação mais ou menos intensa, acarretando estase central e um aumento da circulação periferica.

Os AA. acima, são de opinião, como já havia provado Lewis, que a reação hiperęmica, é consequente á libertação de substancias estruturalmente semelhantes á histamina, ou á propria histamina resultạnte da desintegração das substancias coloidais tissulares.

Exudação - Em consequencia do fenomeno da hiperemia, teremos um aumento do diametro da rede capilar. Havendo vaso-dilatação, ha dim.nuição na velocidade do sangue nos capilares e, a consequencia é or extravassamento de plasma para os tecidos.

Supoz-se antigamente, que a exudação fosșe uma consequencia da vaso-dilatação que, aumentava a abertura dos estomas vasculares. Entretanto, está provado atualmente que o fenomeno da exudação é de natureza fisico-quimilca, consistindo numa mudança da estrutura dos coloides que constituem as paredes vasculares, o que permite uma maior permeabilidade.

A destruição dos tecidos, que desencadeia a inflamação, põe em liberdade uma serie de substancias que agem como fermentos ativàdores do metabolismo icelular. Essa maior atividade do metabolismo, dá lugar a um aumento do gaz carbonico, o que conduz a uma maior concentração de ions $H$, acidificando o foco. Em segundo lugar, ha no centro do foco inflamatorio, o desdobramento da molecula albuminoide e, o aparecimento de novas substancias que acarretam o aumento da pressão osmotica.

Sabemos pelas leis fisico-quimicas que regem o equilibrio dos liquidos que, a super-embebição dos tecidos por um liquido mais denso que normalmente os banha se exteriorisa por um tumor um dos fenomenos cardiais do processo inflamatorio.

Migração leucocitaria - Dissemos que o sangue perde sua velocidade atravez dos vasos dilatados, em hiperemia; como consequencia, teremos o fenomeno da marginação dos leucocitos, que passam a ocupar a periferia da corrente sanguinea. Isto se explica, por terem os globulos brancos um menor peso especifico e tensão superficial
inferior á das hematias. 
Alguns dos leucocitos marginados, não. tardam a se insinuaŕ entre os estomas das celulas endoteliais, passando para o foco inflamatorio, pelo fenomeno da diapedese.

Uma vez fora dos vasos, os leucocitos'se comportam como verdadeiras celulas fagocitarias e absorvem substancias extłanhas, germens, catabolitos e celulas mortas.

Examinando cortes de tecidos, não iremos encontrar no foco inflamatorio, sempre um mesmo tipo de celulas. Normalmente, são os leucocitos neutrofilos que migram mas, outros granulocitos podem ser encontrados no local da inflamação e, conforme o tipo de globulo branco, podemos até certo ponto, fazer o diagnostico da infecção.

Antigamente, considerava-se o fenomeno da migração leucocitaria, como sendo uma capacidade vital, inerente aos globulos brancos. Entretanto, estudos posteriores, mostraram que, as mesmas cansas fisico-quimicas que produzem a exudação, dão lugar á saida dos leucocitos para fora dos vasos. Os leucocitos atravessariam as paredes vasais como as gotas de mercurio atravessam a gelatina, sem alterar a sua estrutura. $O$ acumulo de leucocitos no foco inflamatorio, explicar-se-ia portanto, pelo aumento do $\mathrm{pH}$ e pela elevação da pressão osmotica.

Os fenomenos da fagocitose, podem ser explicados por uma adsorpção de substancias de baixa tensão superficial, que nadam no seio de um liquido de tensão elevada. Assim, uma gota de cloroformio dentro dagua, entrando em contato com um fio de laca, é por este atraida, englobando-o a exemplo do que faz um globulo branco com relação a um bácilo.

Néo-formação celular - Fazendo cortes no seio do tecido inflamado, observamos anatomo-patologicamentè que, as celulas do tecido conjuntivo aí se acham presentes. De acordo com o tipo de celulas individualisadas, teremos ou um processo exudativo ou um processo. proliferativo. Quando, no foco inflamatorio predominam leucocitos emigrados, teremos um processo exudativo, ao passo que havendo predominancia de celulas fixas do tecido conjuntivo, estaremos perante um processo proliferativo.

Em geral, são as celulas mais ativas do tecido conjuntivo, aquelas capazes de desempenhar a fagocitose, as que são necontradas num processo inflamatorio proliferativo. Chamam-se - celulas emigrantes do tecido conjuntivo, sendo conhecidas tambem sob o nome de - macrofagos de Metchnikoff, - poliblastos de Maximow ou histiocitos de Aschoff.

Não são somente essas celulas fixas do tecido conjuntivo que possuem a capacidade de fagocitose, devendo-se distinguir tambem as celulas endoteliais dos vasos e das serosas, denominadas por Aschoff de reticulo-endoteliocitos, componentes do sistema reticulo-endotelial.

A libertação das celulas conjuntivas fixas, dar-se-á pela liquefação da substancia fundamental do tecido onde estão situadas. Deste modo podem acorrer para o foco inflamatorio. 
Do que ficou dito, compreende-se que as reações inflamatoriás não podem se processar sinão no tecido conjuntivo. Na realidade é isto o que se dá: o prạcesso inflamatơrio não pođe se desenvolver sinão neste tecido ou, nos tecidos procedentes do mesenquima. Entretanto, aṕenas os tecidos conjuntivos de sustentação são capazes de apresentar as reações celulares e o substrato caracteristica da inflamação.

O tecido conjuntivo e os vasos, se comportam perante o processo inflamatorio de uma maneira semelhante. Isto poderá ser facilmentte compreendido si dissermẹs que a diferenciação do mesenquima prìmitivo conduz á distinção de quatro tipos de celulas, a saber:

1 - celulas de sustentação;

2 - celulas sanguineas primitivas, de onde se originam as celulas vermelhas e brancas;

3 - os endotelios vasculares e das serosas;

4 - celulas fixas do tecido conjuntivo (migratorias).

Todos estes elementos celulares não são nada mais do que adatações funcionais de uma unica especie celular fundamental, que ora se transforma numa serie, ora noutra.

Os tecidos nobres, não podem em hipotese alguma, ser sede de processos inflamatorios. Os elementos parenquimatosos, tomam parte passiva no decurso da inflamação. Assim, exemplificando, o estabelecimento de um processo inflamatorio na visinhança de celulas do tecido nervoso, ás leva á morte por deficiencia circulatoria, mas não por serem sede de processo inflamatorio.

\section{FATORES QUE DETERMINAM O DECURSO DO PROCESSO INFLAMATORIO}

O decurso de uma inflamação, variará de acordo com os diversós fenomenos que a integram.

$O$ decorrer de uma reaçẳo inflamatoria, variá em primeiro lugar de acordo com a natureza do agente determinante do processo. Podemos afirmar que, quianto mais intensa é a ação destruidora do agente, mas violentos e graves serão os transtornos que se produzem nó foco. Entretanto, não é sỏ a quantidade, mas tambem a qualidadé do agente, que determina o tipo de inflamação. Em geral, cada germen patogenico, tem tendencia a produzir uma forma especial de reação inflamatoria que se exteriorisa clinicamente pelos caracteres do exudato e, pela classe das celulas que aparecem no foco.

O processo inflamatorio variará ainda de acordo com o tecido em que se assesta. Si por exemplo for o tecido osseo, não se nota um grande entumecimento, mas sim a necrose da zona afectada. Nơs tecidos frouxos, pelo contrario, o tumor será mais aparente.

Em terceiro lugar, devemos considerar a reação do organismío frente ao agente etiologico. A estrutura fisica e a composiçãa qui- 
mica do plasma que embebe os tecidos, determinam o decurso intimo da inflamaçãò. Daí a razão porque certos individuos têm maior tendencia a apresentar processos supurativos; emquanto que outros reagem menos intensamente, apresentando manifestações gerais mais ou menos intensas. Uns individuos acusam, no decurso de um processo inflámatorio, elevação da temperatura, emquanto que outros mostram uma temperatura sub-febril. Esta questão é muito mais caracteristiça nos processos cronicos, onde a questão do terreno e da. constituição organica, tem grande importancia. E o caso da tuberculose, por exemplo, que nuns assume a forma produtiva e, noutros, o tipo exudativo.

\section{'TIPOS ANATOMO-CLINICOS DA INFLAMAÇÃ்}

Do jogo de todos os fatores acima mencionados, derivam-se os dois grandes tipos clinicos de inflamação: aguda e cronica.

InFLaMação aguda - E aquela em que o processo inflamatorio, entra em conflito com os produtos naturais elaborados pelo organismo. Se caracterisa pelos quatro sinais cardiais de Celsius: calor, rubor, tumor e dor.

As inflamações agudas, pelo caracter do exudato a què dão nacimento, distinguem-se nos" seguintes tipos:

a) Inflamação serosa — E a que dá lugar a um exudato de cómposição analoga ao plasma sanguineo.

Como neste tipo, predomina uma exudação mais ou menos abundante, ha o seu acumulo entre as malhas do tècido conjuntivo, dando lugar a um entumecimento. Tem decurso rapido e cura-se facilmente.

b) Inflamação fibrinosa - Onde o exudato contem grande quantidade de globulinas mais coagulaveis do plasma, ou seja - fibrinógenio. Esta inflamação processa-se domumente nas serosas. $O$ fibrinogenio que se converte em fibrina coagulada, nem bem o exudato atinge a superficie das serosas ou mucosas, é. evidenciado pela reação de Rivalta.

c) Inflamação purulenta - Caracterisada por intensa diapedese, dando lugàr a um exudato purulento, formado quasi que exclusivamente por leucocitos mortos.

d) Inflamação hemorragica - Na qual a diapedese é tão intensa que as hematias misturam-se ao exudato, por terem atravessado tambem a parede dos vasos ou pela sua destruição.

c) Inflamação gangrenosa - Caracterisada por um exudato fetido, produzida geralmente por germens anearobios.

INFLAMAÇÃo GRONICA - As inflamações cronicas se distinguem por apresentar uma reação inflamatoria que não é tão intensa como no caso anterior. Muitas vezes são consequencia de inflamações agu- 
das que se prolongaram por um "statu quo" entre os agentes produtores e a reação organica.

Em geral, a inflamação cronica possue caracter proliferativo desde o inicio, devido a que os agentes causadores do processo, não têm excessiva virulencia.

\section{INFLAMAÇÕES DEANTE DE CORPOS EXTRANHOS E PARASITARIOS}

Os corpos extranhos microscopicos, provocam em torno de si, reações inflamatorias proliferativas. Ha tambem nestas infląmações cronicas, a presença de celulas gigantes, que parecem ser constituidas por um sincicio de celulas endoteliais ou de elementos afins.

$\mathrm{Na}$ realidade, a celula gigante é um botão carnoso abortivo, porem, com todas as capacidades fagocitarias e de reabsorpção dos botốes carnosos que se vêm nas inflamações proliferativas comuns (tec. de granulação).

Os parasitas animais que penetram no corpo, se comportam mais ou menos como corpos extranhos, provocando tambem proliferações analogas ás anteriores. Apresentam como caracter distintivo, intensa infiltração eosinofila.

\section{TERMINAÇÃO DO PROCESSO INFLAMATORIO}

a) Cura integral - A terminação do processo inflamatorio pode levar á cura integral, isto é, á "restitutio ad integrum". O processo inflamatorio termina deste modo nas inflamações do tipo seroso, pela reabsorpção do exudato, sob a ação dos linfocitos que aparecem tardiamente no foco.

b) Cura com fibrose - No que diz respeito ao tecido conjuntivo o processo inflamatorio nele assestado termina por provocar a sua substituição por um tecido cicatricial. Nesta forma, o retorno completo ao estado normal não é possivel, porque os album noides reconstituidos, não apresentam a mesma estrutura fisica que antes do estabelecimento da inflamação. O tecido conjuntico de súbstituição, é menos elastico, mais seco, mais rigido que o anterior.

c) Estado de inflamação cronica - Um processo inflamatorio, pode terminar ainda por um estado proliferativo, em virtude de se estabelecer um "modus vivendi" entre o organismo e o agente etiologico. I nestes casos que surge com frequencia, uma especie de estado de sensibilisação que, muitas vezes, assume as formas de um estado alergico especif co, tanto assim que com frequencia, uma irritação desses focos dá lugar a reações intensas. 


\section{REPERCUSSAO DO PROCESSO INFLAMATORIO SOBRE O ORGANISMO}

A repercussão do processo inflamatorio sobre o organismo manifesta-se por alterações que podem ser evidenciadas por provas de laboratorio e clinicamente. Essas reações, podem se exteriorisar pela formação de anticorpos (individualisados pelas reações de Wassermann, Vidal etc.); pelo aumento do numero de leucocitos no sangue circulante, originando-se os desvios do hemograma para a direita ou para a esquerda, o que caracterisa diversos tipos inflamatorios; pela elevação da temperatura, causada pela libertação de fermentos que agem sobre o centro termo-regulador ou, pela incentivação do mețabolismo organismo, como mais acertadamente se acredita hoje.

A febre, obedece a tipos mais ou menos caracteristicos, conforme a infecção em foco. Assim uma infecção estreptococica leva certo tempo para evoluir e a febre aparecerá sempre que surja uma nova geração de microrganismos ou, se liberte nova quantidade de toxinas.

\section{SIGNIFICACCAO DO PROCESSO INFLAMATORIO}

Do que ficou dito, concluimos que a inflamação é considerada como uma reação constante de defeza do organismo perante os agentes nocivos externos.

Será a inflamação um sintoma benefico? Não, porque a terapeutica visa todos os meios para evitar a sua manifestação. Si é verdade que se trata de uma reação de defesa organica, não é menos certo que ela se processa independentemente de outras razões, sendo por assim dizer, um fenomeno autonomo. Segundo Leriche - os nossos tecidos nos desconhecem.

\section{TRATAMENTO DA INFLAMAÇÃO}

No que diz respeito á terapeutica da inflamação, consideram-se de um modo geral, os meios mecanicos e os meios farmacologicos.

Entre as meios mecanicos ou cirurgicos, citamos todas as operações qưe tendem a dar vasão aos produtos flogisticos, consistindo via de regra, na evacuação operatoria do foco.

A terapeutica farmacologica, envolve todo o problema da ação dos antisepticos.

Contra os cocos em geral, a medicação ecelente é a - sulfamida. Este agente terapeutico, tem sido associado a outros elementos e, ultimamente o foi á pirìdina, constituindo o corpo 693 de Fournier ou para-anino-fénil-sulfamido-piridina, comercialmente conhecido sob o nome de "Dagenan". 
Empregam-se tambem as injeções de anticorpos e de vacinas para aumentar as defesas do organismo.

$\mathrm{Em}$ anos passados, esteve em voga, or metodo de Bier, que consiste em se provocar na região do processo inflamatorio, um entrave á circulação de retorno, que permitindo o acumulo de sangue no local, pretendia beneficiar grandemente o decurso da inflamaçãu. Seja como for, a terapeutica visa sempre diminuir a irritação dos nenvos sensitivos do foco inflamado e abrandar a hiperemia. Geralmente, empregam-se bolsas de gelo no abdomen, cataplasmas 'e compressas quentes sobre a pele. Todas essas medidas, tendendo a modificar a constituição do foco. Existem mesmo, medidas dieteticas com o fim de fazer variar o equilibrio ionico $\mathrm{Ca}$ e $\mathrm{K}$. Como sabemos, o potassio é ecitador da inflamação, emquanto o $\mathrm{Ca}$ é inibidor. 